\title{
The clinical aspect of overweight on rheumatoid arthritis and disease activity
}

\author{
Haitham Ahmed Taghreed A. Al-Sadoon * khudhair A. khudhair ** \\ College of Medicine University of Tikrit \\ * College of Dentistry University of Al-Iraqia \\ ** College of Medicine University of Tikrit \\ E-mail: haithemahmed359 @gmail.com , doctor88884@gmail.com
}

\begin{abstract}
Objective: To investigate the influence of obesity on disease activity in rheumatoid arthritis patients and to determine a probable connection with the acute phase response.

Materials and methods: The recruited patients satisfied the criteria from the American College of Rheumatology (ACR). To evaluate the body mass index (BMI), anthropometric tests were carried out at the Rheumatology Department at Baquba Teaching Hospital, which has a consultation unit. The serum levels of anti-cyclic citrullinated peptide antibodies (anti-CCP) were measured from blood samples taken through the particle-enhanced (latex) immunonephelometry assays on the genius analyser (CO, Ltd. China) and test kits from IMTEC-CCP-Antibodies. RF screen and serological tests (latex) were carried out to determine the C-reactive protein (CRP), measure $\mathrm{Hb}$ and the total WBCs count, the erythrocyte sedimentation rate (ESR) was also carried out.

Results: The current study findings from the sample of RA patients showed that the proportion of patients falling into the overweight classification (BMI 25-29) was $80.6 \%$ while the obese classification (BMI 30-35) was 33.33\%. Among the RF and ACCP-positive cases, a marginally stronger relationship between the development of RA and the history of obesity was found. Additionally, a significant correlation between acute phase response and free mass was found in RA patients (anti-CCP p-value $\leq$ 0.00021 ESR $p \leq 0.00072 \mathrm{Hb} p \leq 0.00054$, and W.B.C $p=\leq 0.000 .94$, CRP $p \leq 1$ ).

Conclusion: The present study's findings show an elevated prevalence of high body mass among the RA patients. Furthermore, a linear association existed between the fat free mass and the acute phase response.
\end{abstract}

Keywords: Rheumatoid Arthritis, Overweight, anti-cyclic citrullinated peptide antibodies.

*The research extracted from master thesis of Haitham Ahmed M.Sc. Student College of Medicine University of Tikrit.

\section{Introduction}

Rheumatoid arthritis (RA) has been defined as a systemic and chronic autoimmune condition marked by joint inflammation, usually with eventual erosive changes and joint deformities [1]. Obesity is commonly described as the condition in individuals where excess body fat accumulates in their body cells. When the individual's caloric intake is more that their energy expenditure or when they are involved in significantly little physical activity, the excess calories in the body are often stored mostly in the adipose tissues as triglyceride, overweight is often an important predisposing factor for chronic back pain and a number of medical other problems [2]. Extant evidence from both empirical and clinical studies have underscored the relationship between obesity and some chronic conditions like cardiovascular diseases, arteriosclerosis, and type diabetes mellitus [3]. The standard measurement of obesity usually involves measuring an individual's body mass index (BMI) [4], which is a rather easy and commonly employed technique for determining the body fat mass. Consequently, BMI has been popularly used as a common way of recognizing individuals at increased risk of adiposity and similar adverse medical conditions and outcomes [5].

Among the RA patients, the anti-cyclic citrullinated peptides (Anti-CCP) autoantibodies are regularly detected and during inflammation, the citrullination process enzymatically incorporates citrulline into proteins. In recent times, these (Anti-CCP) have proved to be substantial biomarkers and have been used as a critical diagnostic tool for RA from its early stages after the onset of the disease [6]. Although the cause of fibromyalgia is currently unknown, several hypotheses suggested obesity [7]. The measurement of CRP and ESR has been used when determining the acute phase response [8]. ESR and C-reactive protein are most frequently used for disease activity measurement. 


\section{Materials and methods}

The study included 100 subjects, sixty patients (41) were female and 19 were male and the remaining 40 with age (20-35) years and sex matched were the healthy control group. The 60 patients who met the criteria from the American College of Rheumatology (ACR) requirements were selected serially from a return rheumatology outpatient clinic. A potential participant with fever, malignancy, active infection like (urinary tract infection, chest infection gastroenteritis and other connective tissue disease CTD was excluded from the study. The only anthropometric parameter specified in the study was BMI and it was calculated as BMI = weight $(\mathrm{kg}) /$ height squared $\left(\mathrm{m}^{2}\right)[9,10]$. The same measuring tape was used to measure the patients' height and they were all weighed on the same scale, barefoot. The BMI definitions used are the ones developed by the World Health Organization (WHO) in 1997, later published in 2000. The definitions stipulate that the normal weight is from BMI (20 to 24), overweight is from BMI (25 to 29), and obese is from BMI (30 to 35).

Blood sample collection: 10 milliliters $(\mathrm{ml})$ of venous blood was drawn from both the patients and the control group. Seven milliliters $(7 \mathrm{ml})$ of each sample were transferred to $10 \mathrm{ml}$ sterile tubes, centrifuged for 15 minutes at 3000 rounds per minute $(3000 \mathrm{rpm})$ and the serum was tested for CRP, RF, and anti-CCP antibodies. The remaining blood sample $(3 \mathrm{ml})$ were transferred into EDTA tube for total white blood cells (WBCs) count, measurement of hemoglobin $(\mathrm{Hb})$, and determination of erythrocyte sedimentation rate (ESR) [11].

\section{Statistical analysis}

Data were analyzed using computer facility of SPSS/-17. The results were expressed as numbers, percentage, range, and mean \pm SD (standard deviation). Significance of difference was assessed using Student $t$ test (independent) was used for comparisons of continuous data of groups whereas $\chi^{2}$ test for percentage with regression equation for relationship between two qualitative variables, taking $p \leq 0.05$ lowest limit of significance.

\section{Results}

Sixty patients were enrolled in the current study where 41 were female $(68.3 \%)$ and 19 were male (31.66\%) as shown in Table (1), which showed a highly significant difference between the frequency of RF screen among RA \& control individuals. Table (2) outlines a comparison between the percentage distribution of RA patients and the control population's expected percentile distribution. On the distribution of body mass index, the proportion of the RA patients falling into the overweight classification (BMI 25-29) was $80.6 \%$ while the obese classification (BMI 30-35) was $33.33 \%$. The body mass index and acute phase response were determined using the formulas presented in the methods section. In women, a moderate correlation between increased BMI and raised acute phase response was observed (ESR $\mathrm{p} \leq 0.00072, \mathrm{Hb}$ $\mathrm{p} \leq 0.00054$, W.B.C $\mathrm{p} \leq 0.000 .94, \& \mathrm{CRP} \mathrm{p} \leq 1$ ) as illustrated in Tables (3) and (4).

Table (1): Sex distribution of Rheumatoid arthritis (RA) patients

\begin{tabular}{|l|c|c|c|c|c|c|c|}
\hline & \multicolumn{2}{|c|}{ Positive } & \multicolumn{2}{c|}{ Negative } & \multicolumn{3}{c|}{ Control } \\
\hline \multicolumn{1}{|c|}{ SEX } & No. & $\%$ & No. & $\%$ & No. & + ve & -ve \\
\hline Male & 16 & 84 & 3 & 16 & 15 & 0.0 & $40(100 \%)$ \\
\hline Female & 25 & 61 & 16 & 39 & 25 & 0.0 & $40(100 \%)$ \\
\hline Total & 41 & 68.3 & 19 & 31.66 & 40 & 0.0 & $40(100 \%)$ \\
\hline \multicolumn{3}{|c|}{ Chi-Sq $=1.97561$} & \multicolumn{3}{c|}{ P-Value $\leq 0.0001$} \\
\hline
\end{tabular}


Table (2): BMI proportions of sera positive and negative Rheumatoid arthritis patients

\begin{tabular}{|c|c|c|c|c|c|}
\hline B M I & positive & $\%$ & negative & $\%$ & Total \\
\hline $20-24$ & 15 & 57.7 & 11 & 42.3 & 26 \\
\hline $25-29$ & 25 & 80.6 & 6 & 19.4 & 31 \\
\hline $30-35$ & 1 & 33.33 & 2 & 66.66 & 3 \\
\hline Total & 41 & & 19 & 60 \\
\hline \multicolumn{7}{|c}{ Chi-Sq $=21.2683 \quad$ P-Value ** $\leq 0.00061$} \\
\hline
\end{tabular}

Table (3): BMI proportions of sera positive and negative $\mathrm{C}$-reactive protein

\begin{tabular}{|c|c|c|c|c|c|}
\hline B M I & positive & $\%$ & negative & $\%$ & Total \\
\hline $20-24$ & 26 & 100 & 0.0 & 0.00 & 26 \\
\hline $25-29$ & 31 & 100 & 0.0 & 0.00 & 31 \\
\hline $30-35$ & 3 & 100 & 0.0 & 0.00 & 3 \\
\hline Total & 60 & & 0 & 60 \\
& \multicolumn{6}{c}{ Chi-Sq. $=0.000$ P-Value $\leq .000$} \\
\hline
\end{tabular}

Table (4): Difference in hematological results between rheumatoid arthritis patient \&control groups

\begin{tabular}{|c|c|c|c|}
\hline $\begin{array}{c}\text { ESR } \pm \text { SD } \\
\mathbf{m m} / \mathrm{hr}\end{array}$ & $\begin{array}{c}\text { WBC Count } \pm \text { SD } \\
\text { cells per cubic } \\
\text { millimeter }\end{array}$ & gm/dl \pm SD & \\
\hline $63.8 \pm 17.4$ & $10.868 \pm 0.975$ & $18.382 \pm 2477$ & Patients \\
\hline $14.75 \pm 3.89$ & $13.723 \pm 0.826$ & $7.955 \pm 1433$ & Control \\
\hline$\leq 0.00072 *$ & $* \leq 0.00054$ & $\leq 0.00094 *$ & P-Value \\
\hline
\end{tabular}

We found a positive association between overweight and obesity with the risk of developing rheumatoid arthritis. The excess risk found was greater for subjects with grade I obesity, who were (66.7\%) at BMI (3035) more likely to develop RA compared to subjects with normal-weight.as shown in Table (5). 
Table (5): BMI proportions of sera positive and negative anti-cyclic citrullinated peptides

\begin{tabular}{|c|c|c|c|c|c|}
\hline B M I & positive & $\%$ & negative & $\%$ & Total \\
\hline $20-24$ & 15 & 57.7 & 11 & 42.3 & 26 \\
\hline $25-29$ & 18 & 58.1 & 13 & 41.9 & 31 \\
\hline $30-35$ & 2 & 66.7 & 1 & 33.4 & 3 \\
\hline Total & 35 & & 25 & & 60 \\
\hline \multicolumn{7}{|c|}{ Chi-Sq $=12.4 * *$} & \multicolumn{3}{|c|}{ P-Value $\leq \mathbf{0 . 0 0 2}$} \\
\end{tabular}

Table (6): Anti-cyclic citrullinated peptides (U/ml) distribution among studied groups

\begin{tabular}{|c|c|c|c|c|c|c|}
\hline BMI & $\begin{array}{c}\text { Mean } \pm \text { SD } \\
\text { of } \\
\text { BM kg / } \mathbf{m}^{2}\end{array}$ & $\begin{array}{c}\text { Mean } \pm \text { SD of } \\
\text { antiCCP } \\
\text { U/ml(Patients) }\end{array}$ & 95\% CI & $\begin{array}{c}\text { Mean } \pm \text { SD of } \\
\text { BM kg / } \mathrm{m}^{2} \\
\text { of control }\end{array}$ & $\begin{array}{c}\text { Mean } \pm \text { SD of } \\
\text { antiCCP } \\
\text { U/ml(Controls) }\end{array}$ & $\begin{array}{c}95 \% \mathrm{CI} \\
\text { Of control }\end{array}$ \\
\hline$(20-24)$ & $\begin{array}{c}35.05 \\
\pm 12.52\end{array}$ & $\begin{array}{c}30.07 \\
\pm 15.11 \text { bc }\end{array}$ & $\begin{array}{c}22.06 \\
; 38.09\end{array}$ & $\begin{array}{r}17.61 \\
\pm \quad 4.86 \mathrm{c}\end{array}$ & $\begin{array}{r}13.57 \\
\pm 6.36 \quad \text { e }\end{array}$ & $\begin{array}{c}3.75 \\
; 23.39\end{array}$ \\
\hline$(25-29)$ & $\begin{array}{c}34.10 \\
\pm 11.62 * a\end{array}$ & $\begin{array}{r}33.76 \\
\pm 11.10 \text { ab }\end{array}$ & $\begin{array}{c}28.51 \\
; 39.01\end{array}$ & $\begin{array}{c}17.71 \\
\pm 5.88 \mathrm{c}\end{array}$ & $\begin{array}{c}16.74 \\
\pm 5.87 \text { de }\end{array}$ & $\begin{array}{c}11.98 \\
; 21.50\end{array}$ \\
\hline$(30-35)$ & $\begin{array}{c}33.14 \\
\pm 16.08 \text { ab }\end{array}$ & $\begin{array}{r}39.02 \\
\pm 10.24 \text { a }\end{array}$ & $\begin{array}{c}33.09 \\
; 44.94\end{array}$ & $\begin{array}{r}18.76 \\
+2.32 \text { b c }\end{array}$ & $\begin{aligned} & 17.28 \\
\pm & 3.06 \mathrm{~d}\end{aligned}$ & $\begin{array}{c}11.360 \\
; 23.202\end{array}$ \\
\hline
\end{tabular}

$* a=$ significance, $(\mathbf{b}, \mathbf{c})$ slightly significance* $\mathbf{p}<0.001$ 


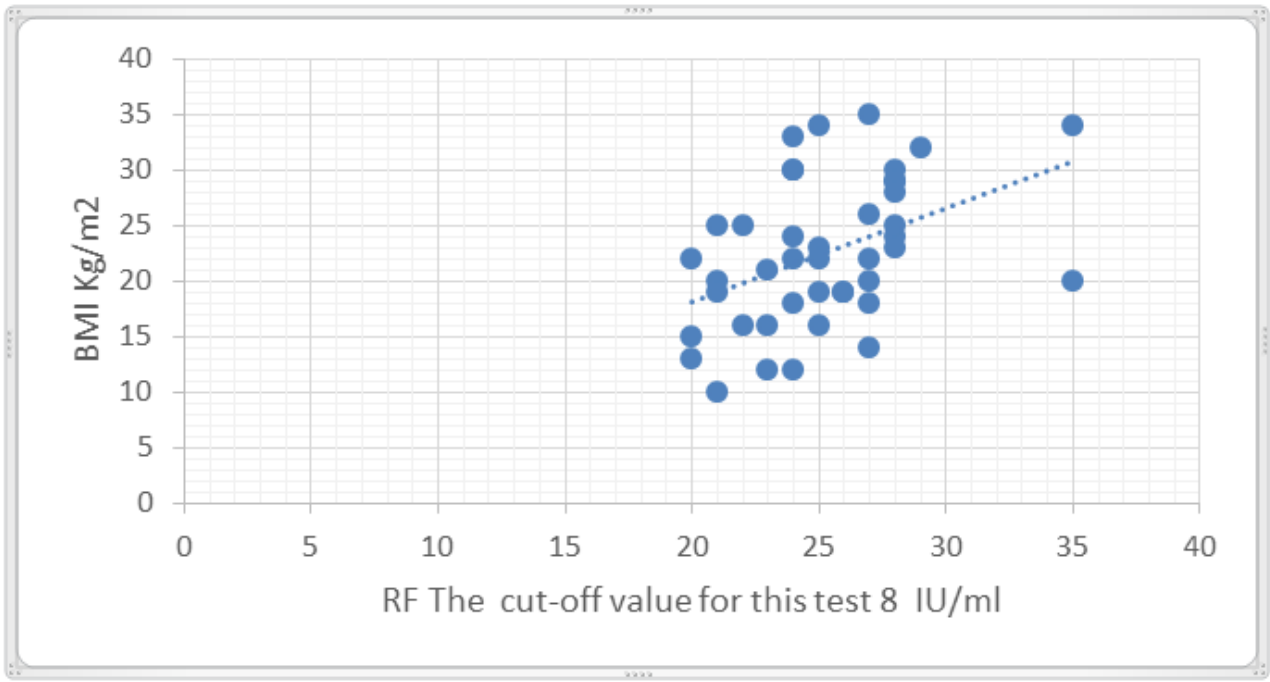

Figure (1): Correlation between BMI and RF

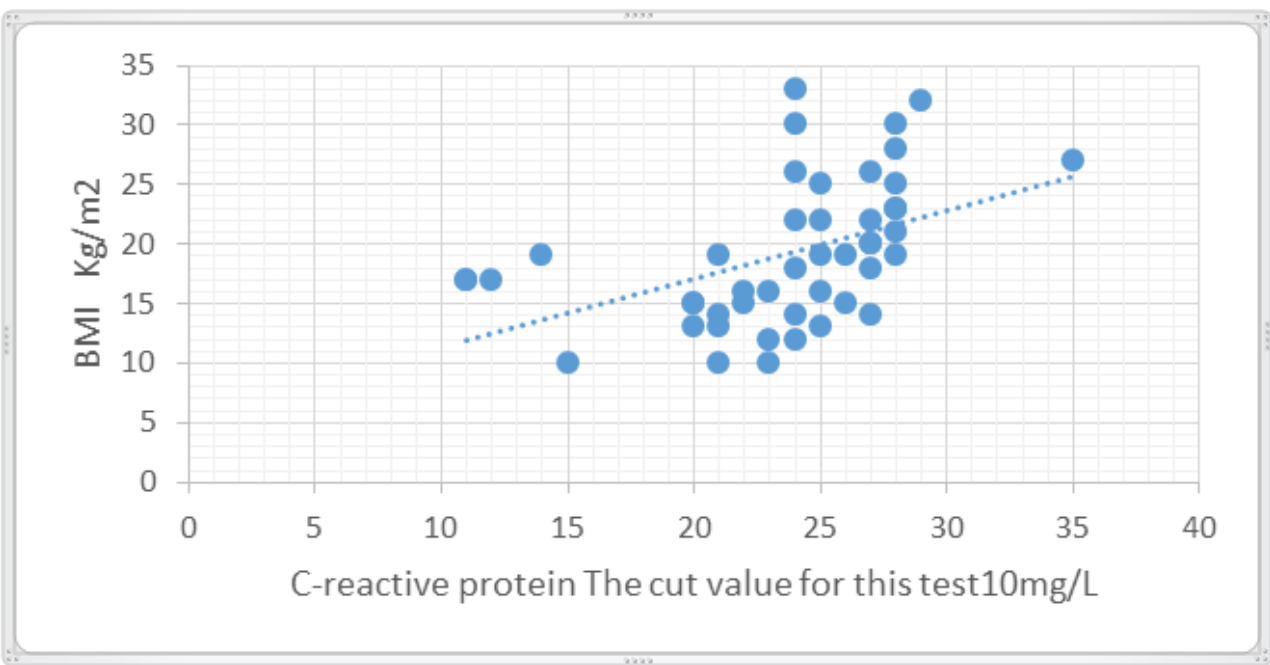

Figure (2): Correlation between BMI and CRP

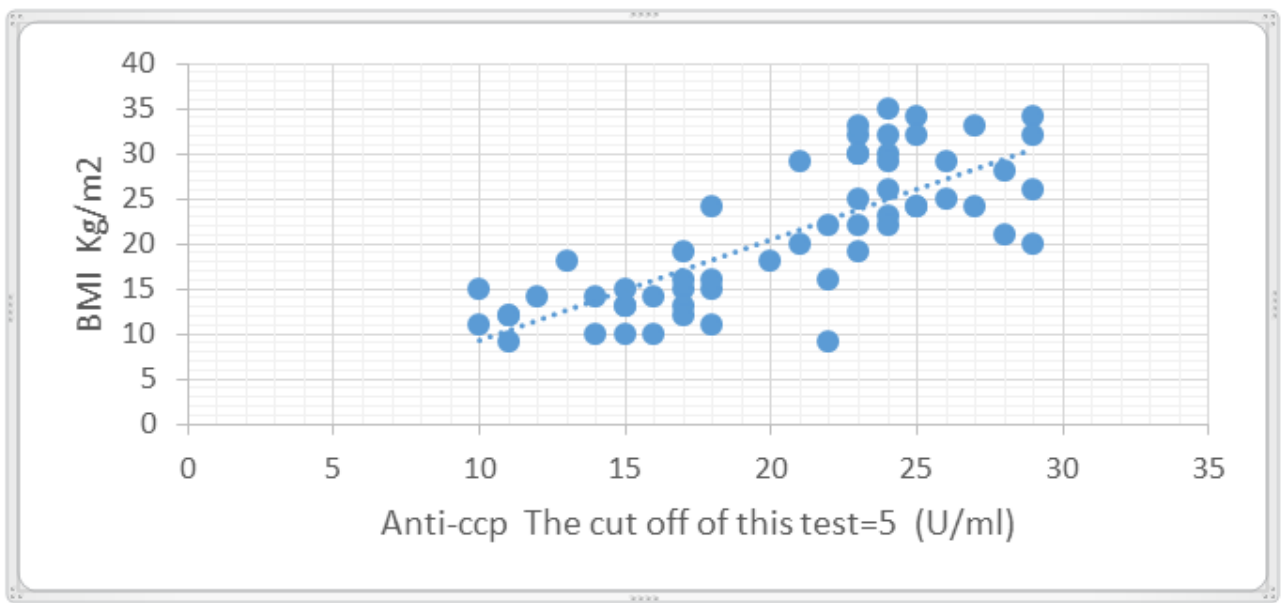

Figure (3): Correlation between BMI and Anti-cyclic citrullinated peptides Anti-CCp 


\section{Discussion}

The results reveal that all RA patients are within the overweight category with a significant difference from the control group and appear within class I obesity. The results corroborate the WHO's Technical Report (2000) findings that showed a highly significant difference in the sample's BMI when compared with the control groups. The results further suggest that RA patients' BMI is a risk factor for other conditions such as fibromyalgia syndrome (FMS) due to chronic inflammation and immunological indices, such as rheumatoid factor(RF) and C- reactive protein (CRP) are a significant relationship between FMS and obesity and that increased BMI is linked to the presence of FMS $[12,13]$. Another Iraqi study showed a significant relationship between FMS and increased BMI [14]. The current study findings showed that $33.33 \%$ of the sample had the highest BMI (30-35), falling under obese classification while $80.6 \%$ of the sample had BMI (25-29), falling under the overweight classification as illustrated in Table (2).

The anthropometry results suggest that the intensification in body mass is highest for RA patients as shown in Figure (1) and (2) and that is comparatively not well-maintained body composition, therefore, measurement of BMI has recently been validated against several diseases and appears to be equally accurate as the more conventional technique. There was a connection between white blood cells (WBC) count and increased acute phase response as shown by the high CRP or ESR. Existing studies highlighted that obese RA patients had higher CRP and ESR levels in contrast with the normal individuals in the control groups, which corroborates the findings of the present study. The level of CRP among the sera of RA patients as outlined in Table (3) highlights a notably high significant difference $(\mathrm{p}<0.001)$ in the CRP levels of the subjects, with the highest level of CRP being among the sera of RA patients (100\%) rather than the other groups $(0.0 \%)$ for the healthy control group. However, a significant difference was not found between the CRP level means among RA sera $(\mathrm{p} \leq 1.000)$ and the healthy control group.

Although the link between obesity and rheumatic arthritis has not been fully established, some possible mechanisms have been suggested. The possibilities include the adipocytes that release adipocytokines and inflammatory cytokines such as CRP, interleukin-6, tumor necrosis factor, leptin, adiponectin, and several other impact inflammations and the significant increase in adipose tissue associated with weight gain [2]. For many years, the objective assessment of disease activity in rheumatoid arthritis has been the assessment of CRP concentration. It is well-known that CRP is a good marker for acute-phase protein and it is elevated in active arthritis. The prognostic value of the persistently elevated CRP levels has been widely accepted now and usually this kind of increased CRP is common in patients with huge risk for continuing joint deterioration and consequently they are in need of supportive care and more aggressive treatment. The findings of this study are in line with that of Otherness [15].

It was further found that among the RA patients, the ESR was significantly higher $(p \leq 0.00072)$ than in the control group. As shown in Table (4), the mean of ESR was $(63.8 \pm 17.44) \mathrm{mm} / \mathrm{hr}$. in RA patients and (14.7 $5 \pm 3.89) \mathrm{mm} / \mathrm{hr}$. in the control group when examining RA patients using either ESR or CRP levels [16]. The connection between RA patients' ESR and disease activity has been evaluated before, the ESR increased as disease activity increased, evaluating the ESR as a predictor of overall disease activity [17]. Hemoglobin levels show a highly significant difference $(\mathrm{p} \leq 0.00054)$ in the mean between patients and control group. Mean of hemoglobin was $(10.868 \pm 0.975) \mathrm{gm} / \mathrm{dl}$ in RA patients and $(13.723 \pm 0.826) \mathrm{gm} / \mathrm{dl}$ in the control group as illustrated in Table (4). RA patients have mild to moderate anemia and this agrees with many other previous studies [18].

The findings of the present study could help in understanding the occurrence of anemia in RA patients. The occurrence could be due to ineffective erythropoiesis, bone marrow suppression, anemia of chronic disease, nutritional effect, drug effect (usually those that affect folate metabolism), and sometimes due to NSAID induced internal bleeding. As stated by Baer and colleagues, anemia of chronic disease is the most popular cause of anemia in RA patients, which is classified as such if the ferritin concentrations reflected enough body iron stores [19]. The effects of inflammatory mediators, specifically the cytokines, has been suggested as the cause anemia of chronic disease, which play a significant role in the impairment of erythropoiesis. Mean of white blood cell count was $(18.382 \pm 2477)$ cells per cubic millimeter in RA patients and (14.7 5 \pm 3.89 ) cells per cubic millimeter in the control group as shown in Table (4). The mean of WBCs was significantly higher $(\mathrm{p} \leq 0.00094)$ in RA patients than in the control group. In RA patients, neutrophil and eosinophilia may result from the inflammatory process, active infection. 


\section{References}

1. Bender D , Mayes P. Overview of Metabolism \& the Provision of Metabolic Fuels. In:

Murray R, Granner D, Rodwell V. 2006; (Eds.) Harper's Illustrated Biochemistry.27 th ed. Singapore, McGraw Hill p.132.

2. Gómez R, Conde J, Scotece M, Gómez-Reino J, Lago F, Gualillo O. What's new in our understanding of the role of adipokines in rheumatic diseases? Nature Reviews Rheumatology. (2011)1;7(9):528-536.

3. Hossain P, Kawar B, El Nahas M. Obesity and Diabetes in the Developing World - A Growing Challenge. New England Journal of Medicine. (2007); 356(3):213-215.

4. Sweeting H. Measurement and Definitions of Obesity in Childhood and Adolescence: A field guide for the uninitiated. Nutr J. (2007);6(1).

5. Mei Z, Grummer-Strawn L, Pietrobelli A, Goulding A, Goran M, Dietz W. Validity of body mass index compared with other body-composition screening indexes for the assessment of body fatness in children and adolescents. Am J Clin Nutr. (2002);75(6):978-985.

6. Raptopoulou A, Sidiropoulos P, Katsouraki M, Boumpas D. Anti-Citrulline Antibodies in the Diagnosis and Prognosis of Rheumatoid Arthritis: Evolving Concepts. Crit Rev Clin Lab Sci. (2007); 44(4):339-363.

7. Dessein P, Shipton E, Budd K. Nociceptive and non-nociceptive rheumatological pain: recent developments in the understanding of pathophysiology and management in rheumatoid arthritis and fibromyalgia. Pain Reviews. (2000); 7(2):67-79.

8. van Leeuwen M, van Rijswijk M, van der Heijde D, et al. The Acute-Phase Response in Relation to Radiographic Progression in Early Rheumatoid Arthritis: A Prospective Study during the First Three Years of the Disease. Rheumatology. (1993); 32(3):9-13.

9. Lawrence R, Helmick C, Arnett $\mathrm{F}$ et al. Estimates of the prevalence of arthritis and selected musculoskeletal disorders in the United States. Arthritis \& Rheumatism. (1998);41(5):778-799.

10. Lee DM, Schur PH. Clinical utility of the anti-CCP assay in patients with rheumatic diseases. Ann Rheum Dis. (2003); 62(9):870-874.

11. Thomas RD, Westergard JC, Hay KL, et al. Calibration and validation for erythrocyte sedimentation rate tests. Roles of the International Committee on standardization in Hematology reference procedure. Arch Pathol Lab Med (1993); 117:719-723.

12. Termeh F, Usha S, Christa L, Kim K . InnesPotential Mediators between Fibromyalgia and C-Reactive protein: Results from a Large U.S. Community Survey BMC Musculoskelet Disord. (2017); 18: 294. 13. Chaiamnuay S, Bertoli A, Fernandez M et al. The Impact of Increased Body Mass Index on Systemic Lupus Erythematosus. JCR: Journal of Clinical Rheumatology. (2007);13(3):128-133.

14. Mohammed H. Alosami Role of Resistin in Patients with Primary Fibromyalgia Journal: Journal of the Faculty of Medicine . (2011); 53(2):152-155.

15. Otterness IG. The value of C-Reactive Protein measurement in rheumatoid arthritis. Semin-Arthritis Rheum.(1994);24(2):91-104.

16. Mehta A ,Hoffbrand (2005),AV.Haematology at a glance. $2^{\text {nd }}$ edn.

Blackwell. Mitchell, R. (2010) Environmental microbiology.

17. Jessica W, Hayley EJ, Jonathan B, Penny W, Chris S, Willie H . Use of multiple inflammatory marker tests in primary care: using Clinical Practice Research Datalink to evaluate accuracy. British Journal of general. Practice (2019); 69 (684): 462- 469.

18. Pinals R, Masi A, Larsen R. Preliminary criteria for clinical remission in rheumatoid arthritis. Arthritis \& Rheumatism. (1981);24(10):1308-1315.

19. Vreugdenhil G, Wognum AW, van Eijk HG, et al .Anaemia in rheumatoid arthritis: the role of iron, vitamin B12, and folic acid deficiency, and erythropoietin responsiveness. Annals of the Rheumatic Diseases (1990);49:93-98. 